\title{
O teatro de revista e a República
}

\section{Luiz Francisco Rebello}

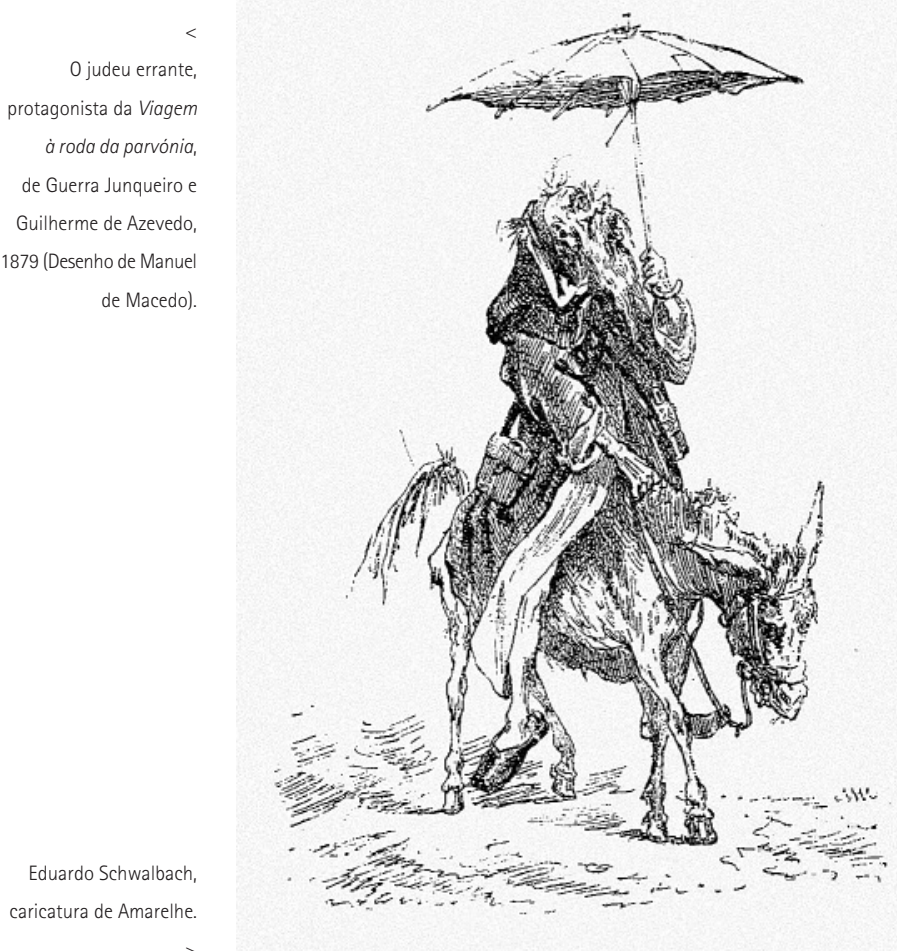

0 cartaz dos teatros de Lisboa anunciava, para a noite de 4 de Outubro de 1910, sete espectáculos, dos quais três eram revistas: Zig-Zag no Teatro Chalet, De olho aberto no Music-Hall, É fantástico no Salão do mesmo nome. Às onze horas da manhã do dia seguinte, a República era proclamada no salão nobre dos Paços do Concelho, e anunciada ao povo da capital por José Relvas, membro do Directório do Partido Republicano eleito em Abril do ano anterior no Congresso de Setúbal com o "mandato de fazer a Revolução". E assim de facto aconteceu.

Durante uma semana os teatros estiveram fechados. E quando a revista do Salão Fantástico retomou a sua carreira, os autores (Pedro Bandeira e Dinis de Melo) acrescentaramIhe uma "apoteose dedicada à República Portuguesa", como faria logo a seguir o Music-Hall. A 13 estreava-se no Casino Étoile uma nova revista, Duras de roer, assinada por Adriano Mendonça e Francisco Rosendo, a que também não faltava uma exaltante "apoteose da República"; e duas revistas do operoso Ernesto Rodrigues (um dos autores de Zig-Zag), Sol e sombra e $A B C$, eram repostas em cena, aquela no Teatro do Príncipe Real, agora denominado Apolo (como o seu homónimo portuense passaria a ser Sá da Bandeira) esta no Avenida, ambas "ampliadas com novos números alusivos à proclamação da República em Portugal". A revista selava assim a sua aliança com o novo regime.

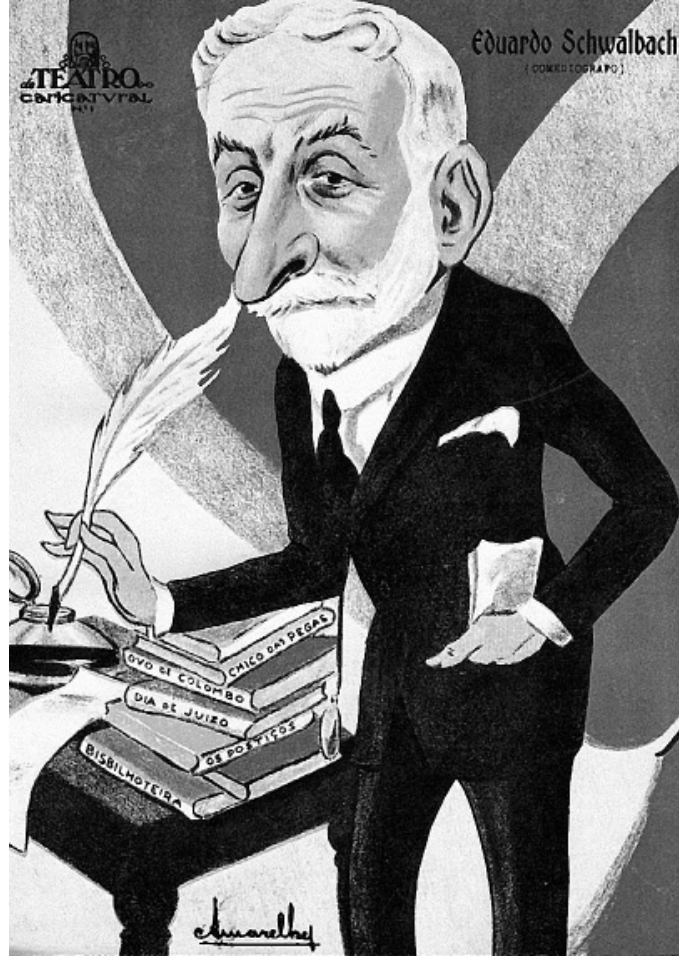

Escrevi "aliança", propositadamente não escrevi "adesão", para evitar a conotação com o termo então cunhado para designar a colagem oportunista à jovem República cujo advento o teatro de revista há muito vinha a auspiciar. Reportando-se aos últimos anos do século XIX e primeiros do seguinte, ou seja, os anos de declínio da dinastia bragantina, Gustavo Matos Sequeira, ele próprio também autor de revistas, observou que esta "entrava a colaborar com os adversários da monarquia, maliciosa, mas discretamente, seguindo sempre ao sabor da corrente, como é da sua própria condição" (Sequeira 1947: 147).

Na realidade, porém, essa colaboração já vinha de trás, e nem sempre primava pela discrição - bem longe disso... Bastará lembrar, entre muitos outros exemplos possiveis, a contundência dos ataques desferidos por Guerra Junqueiro e Guilherme de Azevedo na Viagem à roda da parvónia, em 1879, contra a fraudulência eleitoral e a vacuidade da retórica parlamentar (o que levaria à sua proibição na própria noite da estreia); os apelos de António de Menezes, dois anos volvidos, no último acto de Tuttili-Mundi, a que o Zé Povinho deixasse de ser "o eterno escravo de todas as explorações (...) para ser enfim essa grande força que se chama o Povo!"; ou ainda a exaltada e explícita defesa do ideário socialista e do direito à greve nas revistas "democráticas", como a crítica as definiu, de 

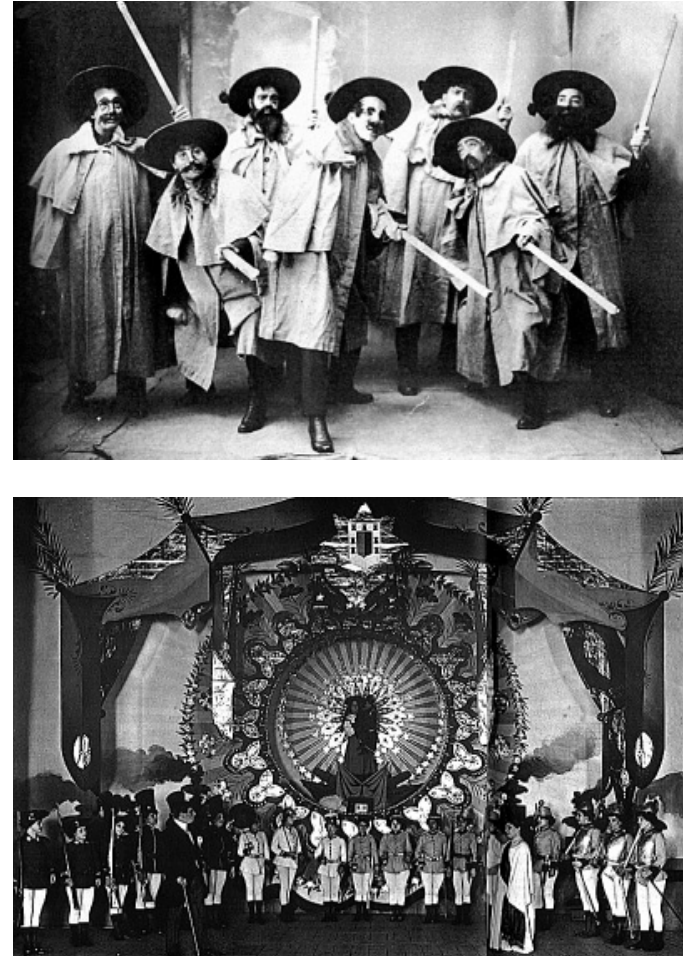

Júlio Rocha (Um rei pequeno, Á roda da política, O Filoxera, Os pontos nos ii, 1882-1886), em que Fontes Pereira de Melo, chefe do Partido Regenerador, era alcunhado de "Bismarck de papelão"... E, à medida que o crepúsculo da monarquia se aproximava, os ataques iam subindo de tom. No quadro de abertura da primeira revista do engenhoso Baptista Dinis, 0 século XIX (1893), cuja acção decorria no fundo do mar, desfilavam sereias, peixesespada, um polvo gigantesco, numa clara alusão às promessas incumpridas dos governantes, às investidas brutais da polícia, ao grande capital "que governava o governo". No Ó da guarda!, de Luis Galhardo e Barbosa Júnior (1907), o ditador João Franco e a sua política repressiva eram alvo de impiedosos remoques e ferozes diatribes ${ }^{1}$. Em Garotices \&t companhia (1907), de Artur Arriegas, futuro adepto do sidonismo, um dueto contrapunha a "Menina Bonita" à "Menina Feia" - e a República era aquela... Na primeira versão de $A B C$ (1908), com que Ernesto Rodrigues começou a sua fecunda carreira de autor de teatro (dito) ligeiro - foi ele o fundador, em 1912, com Félix Bermudes e João Bastos, da famosa "Parceria" que durou até à sua morte em 1926, e a que ficaram a dever-se os grandes êxitos da opereta 0 João Ratão e das farsas o Conde-Barão e O leão da Estrela-, evocava-se a Maria da Fonte para incitar o povo a pegar de novo em armas e lutar pela liberdade. Como, aliás, Marcelino Mesquita e Gualdino Gomes haviam já feito na década anterior em A tourada (1894), sua única incursão nos territórios da revista. E com tal veemência o fizeram que a imprensa afecta ao regime pediu a intervenção da censura...

Nos dezasseis anos de vigência da República democrática, foi a revista, sem dúvida, o tipo de espectáculo teatral com mais assídua participação do público: entre 1911 e 1916 contabilizam-se cerca de 180 títulos, o que corresponde a uma média de 30 por ano. $E_{1}$ das duas vias apontadas por Fialho de Almeida num estudo pioneiro publicado em 1896 nas páginas da Revista teatral - 0 "Panfleto falado, em que o escritor, bem em face da turba, Ihe avergoa nas carnes o látego" e a "súmula por exclusivo picaresca das efemérides do ano, pretexto de coplas, vistas, guarda-roupa e movimento de comparsaria mais ou menos aparatosos" (Almeida 1925: 67-96) - foi, por esta, sem dúvida também, que a revista portuguesa com mais frequência se encaminhou, quer antes, quer depois de 1910. Certo é que nunca se absteve de criticar os desmandos e as mazelas do poder instituído - a instabilidade governativa, as lutas inter- e intra-partidárias, o desequilibrio orçamental, os escândalos financeiros, a carestia da vida, a escassez dos géneros e a especulação dos anos de guerra, assim como a evolução dos costumes e das modas, as novidades literárias e artísticas ${ }^{2}$. Faziao, contudo, as mais das vezes, "sem ofender susceptibilidades nem melindrar os partidos", segundo a confissão do experiente Sousa Bastos, um mestre do género (apud Rebello 1984: 75), cujo reinado se estendeu de 1870 a 1909, rivalizando, a partir de 1896, com Eduardo Schwalbach, o qual, por sua vez, resumiria os limites da crítica revisteira na fórmula "mas nada que possa ferir, I apenas alfinetadas". 0 equilibrio da revista assentava neste pacto compromissório de cumplicidade: as classes dominantes condescendiam em deixar-se risonhamente criticar, as classes desfavorecidas sentiam-se compensadas das suas carências e frustrações ao aplaudir essas críticas. 0 sistema aceitava que the denunciassem os defeitos e os vícios, desde que não Ihe impugnassem os fundamentos.

Os títulos das revistas estreadas após o triunfo da revolução davam constância da mudança operada no país: Tinha que ser, Apoiado!, Vá pela esquerda... No prólogo da primeira, e mais paradigmática, grande revista republicana - Agulha em palheiro, de Ernesto Rodrigues, Félix Bermudes e Lino Ferreira (sob o pseudónimo de Marçal Vaz) -, o velho Portugal aparecia sob as vestes do Doutor Fausto, a quem Mefistófeles dava a beber o elixir da Revolução, concedendo-Ihe assim uma nova juventude e o amor de Margarida, em quem encarnava a jovem
Os trauliteiros, da revista A Traulitânia, 1919.

Apoteose à República da revista Agulha em palheiro (1911)

Um quadro desta revista era constituido por um filme - e seria ele o primeiro filme português de enredo, "O rapto duma actriz", realizado por Lino Ferreira, intercalado na acção da peça.

Mas, sob este último aspecto, o tom era, por via de regra, francamente reaccionário: vejam-se os comentários, de grosseiro mau gosto, suscitados pelo Orpheu e pelas Canções de António Botto, em,

respectivamente, ODiabo a quatro (1915) e Céu aberto (1923), aquela da parceria de Ernesto

Rodrigues, esta da parceria de Luis Galhardo. 
João Franco

interpretado pelo acto Leopoldo Fróis, na revista P'rá frente! (1906).

Luis Galhardo

e Barbosa Júnior autores de Ó da guarda!

Além dos autores citados no texto, devem mencionar-se ainda, pela

sua operosidade no

primeiro quartel do

século, os nomes de Andre Brun, Eduardo Fernandes, Acácio de Paiva, Pereira Coelho, Alberto Barbosa

Xavier de Magalhães, Lourenço Rodrigues e, no Porto, Guedes de Oliveira Arnaldo Leite, Carvalho Barbosa, Abreu e Sousa Ascensão Barbosa. E não pode esquecer-se a colaboração musical dos

compositores Filip Duarte, Manuel Benjamin Luis Filgueiras, Bernardo Ferreira, Tomás Del Negro, Alves Coelho, Carlos Calderón, Hugo Vidal, Wenceslau Pinto, Luz Júnior, Raul Portela..
República. Mas, se é certo que os autores saudavam com entusiasmo a nova bandeira verde-rubra "que nos sorri, grande e guerreira, / como um sol novo", não deixavam todavia de verter uma enternecida lágrima de saudade pela flâmula azul e branca, "tão pura que o bom Deus, p'ra Ihe fazer o véu, / cortou um farrapito ao manto azul do céu"...

Seria errado ver nisto uma contradição: o que se manifesta aqui é a intrinseca ambiguidade da revista, que, ao contrário do que alguns supõem, não é ideologicamente conservadora, até porque nenhum género ou categoria teatral (literária, artística) é, em si mesmo, abstractamente considerado, reaccionário ou progressista. Houve, em Itália um futurismo fascista, e na União Soviética, um futurismo revolucionário. Na Alemanha dos anos 20 do século passado, Piscator concebeu e montou revistas que se inscreviam no espírito e nas intenções programáticas da "agit-prop". E em Portugal, na década anterior, Schwalbach servia-se da revista para, confessadamente, "iniciar o resgate do longo cativeiro em que definhava o nacionalismo português" e recuperar a "Tradição que é o Padre-Nosso da Pátria transmitido de geração em geração, a Ave-Maria de graça e beleza de todo um Povo" (Schwalbach 1945: 306-311). A trilogia formada por 0 dia de juízo, 0 ovo de Colombo e Ao Deus dará (1915-1918), de que foi autor, anunciava e apoiava, no seu delírio patrioteiro, a "República Nova" de Sidónio Pais, e, a dez anos de distância, antecipava o advento do Estado Novo fascista. Mas logo em 1919, no pólo oposto, a "Parceria" chefiada por Ernesto Rodrigues rejubilava com o fracasso da efémera "monarquia do Norte" e da intentona de Monsanto (A Traulitânia), como também faria os festejados autores de Ó da guarda!, Luís Galhardo e Barbosa Júnior, em Aqui d'El-Rei?

Seis anos depois, as parcerias de Rodrigues e Galhardo juntavam-se para proclamar, no quadro final de Rataplan! (1925), que "era preciso um enorme tambor em que o patriotismo viesse tocar a reunir". Como veio a acontecer em 28 de Maio de ano seguinte - e foi uma ditadura que se instalou, para durar quase meio século. Meio século durante o qual os autores voltaram a conhecer "as mil e uma dificuldades de pensar, escrever, realizar e pôr em cena uma revista com a polícia ao lado e a tesoura em cima da mesa de trabalho" a que, numa crónica de 1904 aludia Joaquim Madureira (1905: 330).
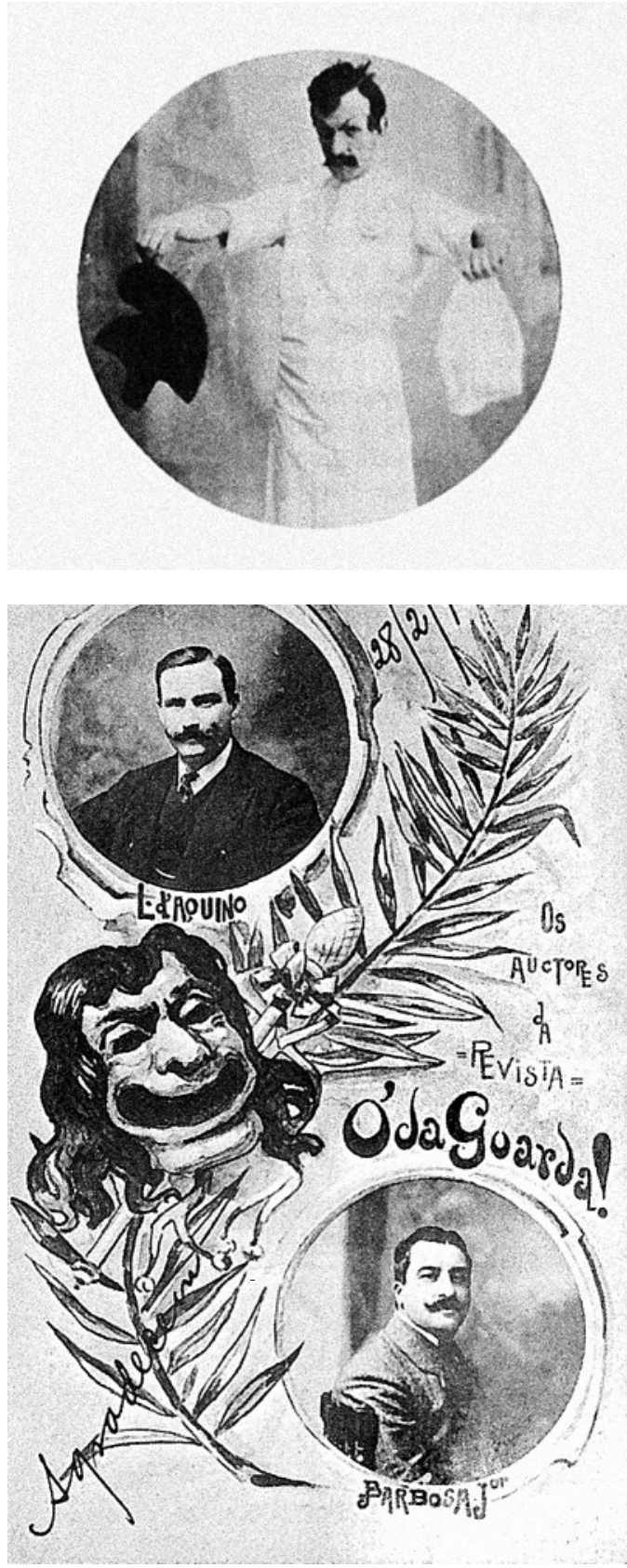

\section{Referências bibliográficas}

ALMEIDA, Fialho de (1925), Actores e autores, Lisboa. BASTOS, Sousa (1908), Dicionário de teatro português, Lisboa. BERJEAUT, Simon (2005), Le théâtre de Revista : Un phénomène culturel portugais, 1851-2005, préface de Luiz Francisco Rebello, Paris, L'Harmattan.

MADUREIRA, Joaquim (1905), Impressões de teatro, Lisboa. REBELLO, Luiz Francisco (1984-1985), História do teatro de revista em

Portugal, Lisboa, Publicações D. Quixote, 2 vols.

SANTOS, Vitor Pavão dos (1978), A revista à portuguesa, Lisboa, 0 Jornal. SARAIVA, Arnaldo (1980), Literatura marginal/izada, Porto, Edições Árvore. SCHWALBACH, Eduardo (1944), Álareira do passado, Lisboa, Edição do Autor. SEQUEIRA, Gustavo Matos (1947), "O teatro de revista", in A evolução e o espirito do teatro em Portugal, $2^{\circ}$ Ciclo das conferências promovidas pelo Século, Lisboa.

Nota redactorial: a grafia deste artigo é da responsabilidade do autor. 